\title{
Individual differences in eyewitness identification accuracy between sequential and simultaneous line-ups: consequences for police practice and jury decisions
}

\author{
Dominic Willmott ${ }^{A, B, C, D, E, F}$, Nicole Sherretts ${ }^{A, C, D, E, F}$ \\ School of Human and Health Sciences, University of Huddersfield, United Kingdom
}

BACKGROUND

Although previous research has indicated that sequential line-up procedures result in fewer mistaken identifications, this was found to be at the expense of accurate identifications more typical within simultaneous procedures. Hence, there remains a lack of agreement about which procedure is superior, and the interaction such procedures have with eyewitness confidence. The interaction between witness demographics and identification accuracy also remains unclear.

\section{PARTICIPANTS AND PROCEDURE}

The opportunistic sample, consisting of 60 people from the general population, was divided randomly into two experimental conditions: simultaneous (SIM) and sequential (SEQ). Participants in the sequential procedure observed 12 photographs, one at a time, deciding if they believed the suspect to be the person shown in the current photograph and unable to return to a given picture once they decided the individual shown was not the suspect described. Participants in the simultaneous condition were shown all 12 photographs concurrently and asked to determine which, if any, of the photographs was the suspect described.
RESULTS

No significant differences were found in identification accuracy between line-up procedures, but significant differences in confidence levels between the two line-up procedures were found. Additionally, analysis of demographic features showed previous line-up experience to be significantly associated with identification accuracy.

\section{CONCLUSIONS}

The present research provides new insight into the interaction of eyewitness confidence between line-up techniques, offering an alternative explanation of witness confidence as well as procedural fairness. Evidence of practice effects increasing the accuracy of identification provides beneficial future implications for police line-up procedures and safer jury decisions, often reliant on identification evidence.

\section{KEY WORDS}

sequential-superiority effect; mock witness paradigm; confidence-accuracy relationship

CORRESPONDING AUTHOR - Dominic Willmott, School of Human and Health Sciences, University of Huddersfield,

Queensgate, HD1 3DH Huddersfield, United Kingdom, e-mail: dominic.willmott@hud.ac.uk

AUthors' CONTRibution - A: Study design - B: Data collection - C: Statistical analysis - D: Data interpretation -

E: Manuscript preparation · F: Literature search · G: Funds collection

TO CITE THIS ARTICLE - Willmott, D., \& Sherretts, N. (2016). Individual differences in eyewitness identification accuracy

between sequential and simultaneous line-ups: consequences for police practice and jury decisions. Current Issues in

Personality Psychology, 4(4), 228-239.

RECEIVED 01.09.2016 · REVIEWED 15.09.2016 · ACCEPTED 22.09.2016 · PUBLISHED 11.10.2016 


\section{BACKGROUND}

Eyewitness testimony has long played an integral role in the apprehension and conviction of offenders (Wells \& Olson, 2003). One common type of evidence witnesses may offer police in the aftermath of a crime is a positive identification of a suspected perpetrator from a line-up. In spite of advances in police technologies and widespread implementation of surveillance cameras throughout British towns and cities, modern day policing remains reliant on eyewitness identifications, with recollections typically forming a major piece of evidence against those accused. Studies have repeatedly shown the powerful influence that eyewitness identifications have on jury decisions of guilt during trial (Cutler, Penrod, \& Dexter, 1990), which is elevated further by witness confidence (Semmler, Brewer, \& Douglass, 2011), with jurors considering eyewitness identifications to be a highly reliable form of evidence (Brigham \& Bothwell, 1983). However, over recent years, a growing body of research and appeal case exonerations have begun to amass, raising important questions surrounding the reliability ascribed to witness identification evidence in court.

Scheck, Neufeld and Dwyer (2000), and Wells, Memon and Penrod (2006), independently examining sentencing exonerations in the United States (US), found that in more than $75 \%$ of cases inaccurate identifications were the key component leading to the wrongful incarceration of innocent suspects. The Devlin Report, commissioned by the British government years earlier and investigating the impact of witness evidence on miscarriages of justice in the United Kingdom (UK), also concluded that mistaken eyewitness identifications were the single biggest factor preceding wrongful convictions (Devlin, 1976). As DNA evidence advanced and became routinely included in criminal cases during the 1990s, doubts surrounding the reliability of eyewitness identifications were corroborated, providing concrete scientific evidence that innocent people had been wrongly convicted of crimes they did not commit (Wells et al., 1998). However, recent figures reported by the Innocence Project (2015), set up to assist with the multitude of DNA exoneration cases emerging, reveal that many innocent people likely remain incarcerated today, with eyewitness misidentifications reported to account for $70 \%$ of all confirmed wrongful convictions to date in the US. Whilst similar statistics are not reliably recorded the world over, such findings undoubtedly highlight the degree of credibility that continues to be ascribed to eyewitness identification evidence, despite demonstrations of how vulnerable such witness testimony can be.

Research attempts to provide greater understanding around how eyewitness misidentifications occur have identified a multitude of perceptual and memory fallibilities underlying such identification errors. Some factors have been shown to be related to individual differences in characteristics of the eyewitnesses themselves, including demographic estimators, and the perceived confidence of witnesses in their identifications (Cutler et al., 1990; Meissner \& Brigham, 2001; Semmler et al., 2011; Wells \& Bradfield, 1999; Wright \& Stroud, 2002; Yarmey, 1993). However, predominately, research findings and debate have centred on the police line-up procedure itself, with differences between procedural techniques found to elicit varying levels of accurate identifications and, more importantly, lower rates of false identifications (Brewer \& Wells, 2006; Lindsay \& Bellinger, 1999; Malpass, Tredoux, \& McQuistonSurrett, 2009; Wells, Steblay, \& Dysart, 2015; Wixted, Mickes, Dunn, Clark, \& Wells, 2016).

\section{LINE-UP PROCEDURES}

\section{Simultaneous line-ups}

Defined by Wells and Olson (2003), police line-ups are considered to be an evidential procedure, whereby a suspected perpetrator of a crime is presented to eyewitnesses among other non-suspect filler individuals, with the aim of determining whether the suspect (termed the target individual) can be identified as the culprit responsible. Traditionally police line-ups in the UK and US involved the live simultaneous presentation of a target individual alongside multiple filler individuals similar in appearance to the suspect accused (Wogalter, Malpass, \& McQuiston, 2004). While live line-ups have largely been replaced by the more typical photo line-ups, the simultaneous 'all-at-once' presentation of line-up members has itself come under scrutiny. Moreover, upon being shown an array of line-up photographs simultaneously, eyewitnesses are asked to decide whether the culprit witnessed committing the crime is present. Research has shown that when asked to make identifications in this format, eyewitnesses tend to make relative judgements about which member of the line-up looks most like the culprit witnessed (Lindsay \& Wells, 1985; Wells, 1984, 2006). However, criticism has arisen surrounding use of such a procedure that results in one member of the line-up always more closely resembling the actual offender witnessed than other individuals present, whether the actual culprit is present or not.

Research has suggested that simultaneous procedures may themselves account for false identification errors, with study findings indicating that although this type of line-up appears to increase accurate identifications when the culprit is present in the lineup, the procedure is in fact significantly more likely to lead to mistaken identifications when the culprit is not present (Steblay, Dysart, Fulero, \& Lindsay, 2001; 
Wells, 1993). Undertaking target absent line-up experiments where eyewitnesses were shown a simultaneous photo array without the perpetrator present led researchers to conclude simultaneous procedures to be unfairly biased towards police suspects in that, irrespective of guilt, the more closely an individual resembles the witnessed perpetrator in comparison to other line-up members, the more likely they are to be identified as the culprit responsible (Lindsay \& Bellinger, 1999; Kneller, Memon, \& Stevenage, 2001; Dysart \& Lindsay, 2001). Furthermore, this outcome becomes more prevalent where witness memory is imperfect or incomplete (McQuiston-Surrett, Malpass, \& Tredoux, 2006).

\section{Sequential line-ups}

Attempting to improve upon such procedural limitations associated with relative judgement identifications, an alternative technique was devised, aiming instead to encourage absolute judgements. Central to Lindsay and Wells' (1985) sequential line-up procedure is that witnesses view line-up members 'oneat-a-time', being required to make a decision for each individual, prior to moving on to another and unable to return to those members previously rejected. Eyewitnesses also remain unaware of the number of individuals present in the line-up in an attempt to further encourage an absolute judgment process deemed necessary for improving accuracy of identification (Lindsay, Lea, \& Fulford, 1991). Numerous empirical studies have sought to examine the effects of sequential versus simultaneous line-ups on identification accuracy, with results predominately supporting the notion of a sequential superiority effect (Lindsay \& Wells, 1985; Melara, DeWitt-Rickards, \& O’Brien, 1989; Wells, Steblay, \& Dysart, 2015). In a carefully devised comparative study examining the two differing procedures, Cutler and Penrod (1988) reported finding that the sequential procedure significantly reduced false identifications and increased correct rejections of line-ups, when the culprit was not present (target-absent conditions). In a major meta-analytic review of the opposing line-up procedures, Steblay et al. (2001) examined 23 studies, which compared the techniques across over four thousand experimental participants, and concluded that although the simultaneous procedure obtained significantly more correct identifications overall, the sequential procedure elicited significantly fewer mistaken identifications for both target-present and target-absent line-ups. In fact, when psychologists considered experts in the field were surveyed about how reliable they deemed the sequential presentation format to be in eliciting accurate identification evidence, the findings revealed that over $80 \%$ believed the superiority of the sequential line-up to be reliable enough to be used as evidence in court (Kassin, Tubb, Hosch,
\& Memon, 2001). The implications of such findings are undoubtedly evident in the wide ranging uptake of the procedure within Western legal systems, with recent figures revealing that $32 \%$ of law enforcement agencies in the US now use the sequential line-up type (Police Executive Research Forum, 2013). New Jersey, North Carolina and Illinois have adopted the procedure as the gold standard line-up technique throughout the entire states and across all policing agencies (Carlson, Gronlund, \& Clark, 2008).

Despite wide ranging empirical support and practical implementation of the procedure, research has recently begun to identify potential limitations of sequential line-ups. Criticism has centred on the apparent trade-off between fewer mistaken identifications at the expense of accurate identifications. Meta-analytic results have generally shown that, while the procedure elicits fewer misidentifications when a perpetrator is not present in a line-up, fewer accurate identifications are also made when the perpetrator is present in the line-up, resulting in missed opportunities to identify culprits responsible (see Steblay, Dysart, \& Wells, 2011). Wells et al. (2015) also found that, when examining procedural difference effects on real witnesses of crime randomly assigned to either simultaneous or sequential techniques across four policing districts, previously acknowledged benefits of sequential procedures were not significantly different from simultaneous procedures in that rates of mistaken identification remained highly similar between the two line-up types. Similar findings led Malpass et al. (2009) to question whether the uptake of sequential procedures was more explicable as a wholesale promotion technique, deriving from supportive research largely conducted by the pioneers of the procedure, than as a result of a strong empirical grounding. Ebbesen and Flowe (2002) account for the supposed sequential superiority effect as merely the result of the more cautious nature of witnesses undertaking this type of line-up, who, as a result of making fewer choices in general from target-present and target-absent line-ups, make fewer false identifications overall. In line with such a viewpoint, Meissner, Tredoux, Parker and MacLin's (2005) research identified similar decreases both in correct and false identifications for sequential line-ups when compared to simultaneous line-ups. This led the authors to conclude that despite a conservative change in response criterion, little change has correspondingly occurred in identification accuracy, suggesting that differences observed are the result of a generally reduced witness willingness to make a selection. Although, arguably, a reduced willingness to make a selection not wholly based on a strong memory trace of the perpetrator's identity may be a desirable outcome in order to reduce false identifications, where the procedural construction of line-ups is shown to intrinsically discourage identifications overall, the sequential superiority 
effects are likely to be brought into question. A result of such criticisms and lack of agreement within the research has led many scholars to conclude that debate surrounding the negative or superiority effects of any one procedure (termed system variables - Wells, 1978) remains to be conclusively settled. Further research exploration is undoubtedly required in order to better understand and justify the use of any one approach - a position more apparent when considering the rapid and increasing uptake of sequential line-up procedures throughout Western justice systems (Police Executive Research Forum, 2013).

\section{EYEWITNESS CONFIDENCE}

While debate continues on whether variants of lineup procedures provide superior identifications, the literature concerning the relationship between eyewitness confidence and identification accuracy has been amassing. The appealing nature of a confident eyewitness has been consistently observed to influence both the general public's belief in events that a witness described (Brigham \& Bothwell, 1983; Deffenbacher \& Loftus, 1982) and juror beliefs about the accuracy of such a testimony (Bradfield \& Wells, 2000; Lindsay, Wells, \& O'Connor, 1989; Semmler et al., 2011). In fact, research has provided strong evidence that eyewitness confidence in identifications may in fact be the greatest predictor of verdict outcomes at trial (Cutler et al., 1990), with reliance on witness confidence shown to be unaffected by traditional safeguards, such as cross-examination (Penrod \& Cutler, 1995). Within the United States, the Supreme Court held that the confidence of eyewitness testimony can be used as a measure of its reliability, alongside determining whether such evidence can be considered admissible during trial (see Dobolyi \& Dodson, 2013).

In spite of such apparent unwavering dependence on eyewitness confidence, traditionally the results of mock crime studies found little evidence of a relationship between witness confidence and identification accuracy (Bothwell, Deffenbacher, \& Brigham, 1987; Wells \& Murray, 1984; Wells \& Olson, 2003). However, research contradicting these findings has begun to take precedence, instead accounting for the lack of any significant relationship as resulting from the complex interaction of confidence as a function other factors. Similarity of mistakenly identified individuals to the actual perpetrator responsible, strength of the initial memory trace, and distinctions between those who choose to make an identification versus those who did not, have all been found to negate non-significant confidence-accuracy findings (Deffenbacher, 1980; Lindsay, 1986; Sporer, Penrod, Read, \& Cutler, 1995). Recent research also obtained evidence that, when examining the relationship between confidence and identification accuracy in genuine police line-up situations, confi- dence becomes a highly significant and reliable indicator of correct identification (Wixted et al., 2016).

Attempts to develop the confidence-accuracy relationship further have recently begun questioning whether differences may exist in witness confidence ratings for identifications made between simultaneous and sequential line-up procedures. The theorising behind such a notion stems from the assumption that the stricter absolute judgement criterion associated with sequential line-up identifications demands greater use of quality memory information and, therefore, where identifications are made, they are likely to be indicative of a confident decision process (Wells \& Olson, 2003). Fundamentally, the belief is that when sequential line-up identifications are made, they are likely to be made more confidently because of the additional caution associated with decisions made against one individual at a time. One recent study which set out to directly test this assumption found evidence corroborating such an effect whereby, consistent with previous research, the sequential procedure did produce fewer mistaken identifications than the simultaneous procedure; however, it also produced higher confidence in identifications, even where such selections were inaccurate (Dobolyi \& Dodson, 2013). Although contemporary findings generally display evidence in favour of a relationship between eyewitness confidence and identification accuracy, further research is undoubtedly required to examine the complexities of such a relationship and re-examine Dobolyi and Dodson's (2013) recent results. An alternative assertion that appears intuitively appealing to that made by the aforementioned authors may be that confidence in identification is in fact greater with simultaneous line-ups resulting from eyewitnesses making relative judgements and thereby being required to apply comparative logical assessment of each line-up member rather than an abstract identification made sequentially. What is certain, however, is the need for greater understanding through research exploration, as real world evidence and cases (see Garrett, 2011) continue to indicate the damaging consequences associated with fallibilities in eyewitness identification.

\section{INDIVIDUAL DIFFERENCES IN IDENTIFICATION ACCURACY}

The relationship between eyewitness characteristics and identification performance has historically appeared complex and inconsistent. Termed estimator variables (Wells, 1978), the effects of eyewitness demographics have produced mixed findings concerning the influence of such factors on identification accuracy. Early explorations provided some support that females were more likely to make accurate identifications than males, alongside displaying a slightly 
greater propensity to make a culprit selection generally, in itself appearing to correspond to increased levels of misidentification (Shapiro \& Penrod, 1986). However, overall findings commonly show no significant gender differences in line-up accuracy (Wells \& Olson, 2003). Perhaps somewhat surprisingly, research to date has also failed to demonstrate any relationship between eyewitness intelligence or occupation and identification performance (see Brown, Deffenbacher, \& Sturgill, 1977). One factor that has however obtained some support of being an important determinant of identification accuracy is witness age. Studies have consistently shown that young children and the elderly perform significantly worse than young adults overall, although this appears to be moderated by the presence of the culprit. Moreover, Pozzulo and Lindsay (1998) found that within target-present lineups, identification accuracy is similar to that of young adults, but when targets are absent from line-ups, mistaken identifications are committed at significantly higher rates than with younger adults. Research also suggests that witness age relative to the age of the culprit correlates with accuracy levels, in that eyewitnesses are better able to identify culprits of a similar age to themselves in target-present line-ups than individuals of a different age group (Wright \& Stroud, 2002; Yarmey, 1993). Complicating this relationship, further recent findings show that when controlling for variations in line-up types (e.g. simultaneous vs. sequential), older eyewitnesses are consistently worse than younger witnesses at both accurately identifying culprits from target-present line-ups, alongside accurately rejecting culprits within target-absent line-ups (Erickson, Lampinen, \& Moore, 2016). While the findings show that age does have important implications for identification accuracy, with few direct examinations described in the literature, further research is required to better understand the potential interaction between age and differing line-up types (e.g. simultaneous and sequential). Interestingly, although a body of research has begun to develop indicating the increase in identification accuracy of police officers with experience (see Wells et al., 2006), to the authors' knowledge, no research exists examining the potential beneficial effects of previous line-up experience on eyewitness identification performance. Further exploration of the influence of demographic estimators discussed on eyewitness performance is therefore required, in order to examine whether such individual differences may have a significant impact on identification accuracy.

\section{THE CURRENT STUDY}

Wrongful conviction DNA exonerations and research examinations to date have shown eyewitness identifications to exert a powerful influence on trial outcomes. Whilst previous research has indicated that sequential line-up procedures result in fewer mistaken identifications, the findings have shown this to be at the expense of accurate identifications more typical within simultaneous procedures. Yet, in spite of wide ranging uptake of sequential procedures throughout western law enforcement agencies, a lack of agreement remains concerning the supposed superiority effect of any one line-up technique, and the interaction such procedures may have with eyewitness confidence. Full understanding of the interaction between eyewitness demographics and identification accuracy also remains unclear. Therefore, the main objective of the current study was to examine whether significant differences occur between sequential and simultaneous line-up procedures when the component of memory is removed. Previous research has successfully adopted Doob and Kirshenbaum's (1973) mock witness paradigm (explained in more depth in the method section) in order to explore aspects of line-up procedural fairness (Tredoux, 1999; Valentine \& Heaton, 1999). However, little research has applied such a paradigm to a genuine criminal event utilising the actual array of line-up photographs shown to the eyewitnesses during the original police investigation. It is hypothesised that, upon removing the memory component from witness line-ups, the sequential line-up procedure will be significantly more likely to lead to identification accuracy overall than the simultaneous line-up procedure, where a superiority effect exists. In addition, based on recent research findings it is predicted that sequential line-up procedures will show significantly greater eyewitness confidence in identification than the simultaneous line-up procedure and that there will be a significant relationship between confidence and identification accuracy. Finally, demographic features and previous line-up experience will be tested to examine any significant relationship with identification accuracy.

\section{PARTICIPANTS AND PROCEDURE}

\section{PARTICIPANTS}

The study adopted an independent measures design and utilised an opportunistic sample of 60 people from the general population (males $n=30$, females $n=30)$, ranging in age from 18 to 62 years $(M=32.15$, $S D=12.99$ ), and varying widely in occupation and educational background. Participants were recruited through the use of advertising posters distributed throughout a city centre in the midlands of England, with all those who responded being re-contacted to arrange participation. Participants were randomly assigned to experimental conditions - a simultaneous condition (SIM) and a sequential condition (SEQ) 
- upon arriving on the day. No individuals or particular groups of people were excluded from participating, although it was to be noted if any participant manifested possibly confounding factors, including known memory or information processing defects, or serious eyesight problems, to ensure that such factors did not affect the experimental results. However, no such conditions were known to be present within any of those who responded or took part.

\section{PROCEDURE}

The study made use of Doob and Kirshenbaum's (1973) mock witness paradigm, whereby participants who have not previously seen the offender in question, but have simply been given information about the culprit, are tested. Upon arrival participants were taken individually to a room located on the university campus which had been set up to loosely resemble a police station interview room in that it contained just a desk, a recording device and two chairs. Participants were then informed that they would be required to view a series of photographs, which constituted the police line-up procedure for a crime that they would shortly be informed about. Utilising the same methodology as that adopted within past research (see Wells \& Brandfield, 1999) a brief standardised description of the culprit convicted of the offence was then given to participants based on a description given by a witness at the time alongside a more detailed account of the crime that the perpetrator had carried out. Participants in the sequential line-up condition were informed that they would observe 12 photographs, one at a time, and could observe all photographs twice before being asked to make a decision on each picture in turn, about whether they believed the suspect to be the person shown in the current photograph. In line with current UK and US sequential police line-up procedures, participants were informed that they could not return to a given picture once they had decided the individual shown was not the suspect described. Participants in the simultaneous line-up condition were shown all 12 photographs at once and asked to make a decision about which, if any, of the photographs they believed to be suspect. All subjects were informed that they could take as much time as they liked to view the photographs before selecting which picture they believed to be the individual convicted of the crime described to them. Mock witnesses had not previously seen the offender in question, but were simply given standardised information about the culprit and the violent offence for which they were responsible used in the experimental conditions, in line with the mock witness paradigm. This standardised information was detailed to participants prior to observing line-up photographs within the varying experimental conditions. The purpose of using the mock witness paradigm was to remove the memory trace component from the experimental conditions, in order to test whether any aspect of the line-up construction itself would influence witness identifications. After making an identification, participants were immediately asked to rate how confident they were in the accuracy of their selection on a fivepoint Likert scale, whereby one represents 'very unconfident' and five represents 'very confident'. Participants were immediately asked for such confidence ratings, as a means of ensuring that any post-selection feedback or experimenter interaction did not influence such ratings. Similarly, experimenters themselves were blind from knowing which photo from the array of line-up pictures was the target-culprit, as a further control measure to reduce any experimenter bias effects. Some controls were undertaken in an attempt to ensure that any differences observed in the results could be attributed to differences between the experimental conditions, including standardising the instructions given to participants for each of the conditions, and minimising use of any corroborative feedback language given to participants throughout the experimentation and after line-up identifications have been made. All British Psychological Society (2014) ethical guidelines were adhered to throughout the duration of the research, alongside conforming to the provisions of the Declaration of Helsinki, applicable to research with human subjects (World Medical Association, 2013).

\section{MATERIALS}

Two sets of the same 12-photo array of line-up pictures, containing the target individual convicted for a serious violent crime theat took place in the UK alongside 11 other filler individuals, were shown to participants. These were presented on one sheet of A4 paper for the simultaneous condition, and presented as 12 individual photos for the sequential condition. Photographs were the same as those pictures used in the real line-up procedure, which eyewitnesses to the aforementioned violent offence were shown, in order to assess the reliability of such photos between the differing line-up procedures. A Dictaphone handset and desktop computer were used to record and transcribe participant selections within experimental conditions. Participant response forms were also employed to record participant age, level of education, occupation, any previous experience of police line-ups, culprit selections, and corresponding confidence ratings.

\section{ANALYSIS}

Frequencies, descriptive statistics, and Pearson $\chi^{2}$ tests for independence were calculated using 
Table 1

Demographic information and descriptive statistics

\begin{tabular}{|c|c|c|c|}
\hline Variable & $N(\%)$ & $M(S D)$ & Range \\
\hline Age (continuous) & & $\begin{array}{c}32.42 \\
(13.05)\end{array}$ & $18-67$ \\
\hline \multicolumn{4}{|l|}{ Age groups } \\
\hline $18-25$ & $28(46.70)$ & & \\
\hline $26-35$ & $14(23.30)$ & & \\
\hline $36-45$ & $3(5.00)$ & & \\
\hline $46-59$ & $12(20.00)$ & & \\
\hline $60+$ & $3(5.00)$ & & \\
\hline \multicolumn{4}{|l|}{ Level of education } \\
\hline Below degree level & $24(40.00)$ & & \\
\hline Above degree level & $36(60.00)$ & & \\
\hline \multicolumn{4}{|l|}{ Occupation } \\
\hline Unemployed & $3(5.00)$ & & \\
\hline Student & $21(35.00)$ & & \\
\hline $\begin{array}{l}\text { Employed - } \\
\text { unskilled }\end{array}$ & $18(30.00)$ & & \\
\hline Employed - skilled & $18(30.00)$ & & \\
\hline \multicolumn{4}{|l|}{$\begin{array}{l}\text { Experience } \\
\text { of real line-ups }\end{array}$} \\
\hline Yes & $15(25.00)$ & & \\
\hline No & $45(75.00)$ & & \\
\hline \multicolumn{4}{|l|}{ Confidence level } \\
\hline Very unconfident & $15(25.00)$ & & \\
\hline Unconfident & $9(15.00)$ & & \\
\hline $\begin{array}{l}\text { Neither unconfi- } \\
\text { dent nor confident }\end{array}$ & $18(30.00)$ & & \\
\hline Confident & $18(30.00)$ & & \\
\hline $\begin{array}{l}\text { Very confident } \\
\text { Identification } \\
\text { accuracy }\end{array}$ & $0(0)$ & & \\
\hline Accurate & $2(3.30)$ & & \\
\hline Inaccurate & $58(96.70)$ & & \\
\hline
\end{tabular}

Table 2

Chi-square results showing the association between line-up type and identification accuracy

\begin{tabular}{lcc}
\hline & \multicolumn{2}{c}{ Line-up type } \\
\hline $\begin{array}{lcc}\text { Identification } \\
\text { accuracy }\end{array}$ & Simultaneous & Sequential \\
\hline Yes & $2(3.30 \%)$ & $0(0 \%)$ \\
No & $28(46.70 \%)$ & $30(50.00 \%)$ \\
\hline
\end{tabular}

Note. $\chi^{2}=2.07, d f=1$. Numbers in parentheses indicate column percentages.

SPSS 22. Pearson $\chi^{2}$ tests for independence, as the recommended method for exploring relationships between two categorical variables, were applied in order to explore the associations between: line-up procedure (simultaneous or sequential) and identification accuracy, line-up procedure and confidence level, and participant demographics and identification accuracy.

\section{RESULTS}

\section{DEMOGRAPHIC PROFILE AND DESCRIPTIVE STATISTICS}

A demographic profile of participants, as well as descriptive statistics, is presented in Table 1. Most participants have an above university degree level of education (60\%), are employed (60\%), and do not have prior experience of real line-ups $(75 \%)$.

\section{CHI-SQUARE TEST OF ASSOCIATION}

Chi-square tests for association were conducted to help determine if there were significant relationships between: identification accuracy and line-up type; confidence level and line-up condition; and identification accuracy and remaining demographic variables.

There was no significant association between the type of line-up procedure undertaken and identification accuracy for either simultaneous or sequential line ups, $\chi^{2}(1, N=60)=2.07, p=.150$. The observed frequencies in both simultaneous and sequential lineup accuracy scores were, therefore, not significantly different from the frequencies that could be expected in the differing line-up conditions by chance (Field, 2009) see Table 2.

The results reveal a statistically significant difference in confidence level between simultaneous and sequential line-up conditions. The association between these variables was significant and strong, $\chi^{2}(3, N=60)=24.00, p<.001$, Cramer's $\mathrm{V}=.63$. Among participants in the simultaneous condition, fewer were very unconfident and more were confident with their decision than would be expected. Conversely, there were more participants in the sequential condition who were very unconfident and fewer who were confident than would be expected (see Table 3). The results show no statistically significant difference in identification accuracy between levels of confidence, $\chi^{2}(3, N=60)=4.83, p=.185$. These results suggest that the rate of identification accuracy is similar for participants who were very unconfident, unconfident, neither confident nor unconfident, and confident.

Further tests of association were also conducted on participant demographics and identification accuracy to investigate whether any estimator variable frequencies differed significantly in identification accuracy.

The findings show no statistically significant differences in identification accuracy between age groups, $\chi^{2}(4, N=60)=2.73, p=.603$. These results suggest that the rate of identification accuracy is similar for participants in the 18-25, 26-35, 36-45, 46-59, and $60+$ age groups.

Chi-square results revealed no statistically significant differences in identification accuracy between 
males and females, $\chi^{2}(1, N=60)=2.07, p=.150$. These results indicate that the rate of identification accuracy is similar for male and female participants.

The test of association results indicate that identification accuracy does not appear to be statistically associated with level of education. There were no statistically significant differences in identification accuracy between those with an education below degree level and those with an education above degree level, $\chi^{2}(1, N=60)=0.09, p=.769$, suggesting that the rate of identification accuracy is similar for participants with below degree level of education and above degree level of education.

The findings reveal no statistically significant differences in identification accuracy between types of occupation, $\chi^{2}(3, N=60)=1.13, p=.769$, thereby indicating that the rate of identification accuracy is similar for students, unemployed participants, participants employed in skilled professions, and participants employed in unskilled professions.

The test of association results indicate that identification accuracy is statistically associated with previous line-up experience; the results show a statistically significant difference in identification accuracy between previous line-up experience and no previous line-up experience. The association between these variables was significant and moderate, $\chi^{2}(1, N=60)$ $=6.21, p=.013$, Cramer's V = .32. Among participants who had previous experience of real line-ups, there were more who were accurate than expected (see Table 4).

\section{DISCUSSION}

Adopting the mock witness paradigm, the present study sought to further investigate the relationship between sequential and simultaneous line-up procedures and identification accuracy. Additionally, this study aimed to examine the association between varying line-up types and eyewitness confidence in identification, as well as assessing any potential relationships between witness demographics and identification accuracy.

Along with the participant response form, photos previously described (see method section) were used to examine the relationships between line-up procedure (simultaneous or sequential) and identification accuracy, line-up procedure and confidence level, and participant demographics and identification accuracy after standardised descriptions of the target culprit were given. The results revealed no significant relationship between the type of line-up procedure undertaken and identification accuracy for either simultaneous or sequential line-ups; participants in the sequential line-up condition were no more accurate in their identifications than those in the simultaneous line-up condition. Such findings
Table 3

Chi-square results showing the association between line-up type and confidence level

\begin{tabular}{lcc}
\hline & \multicolumn{2}{c}{ Line-up type } \\
\hline Confidence level & Simultaneous & Sequential \\
\hline Very unconfident & $0(0 \%)$ & $15(25.00 \%)$ \\
Unconfident & $6(10.00 \%)$ & $3(5.00 \%)$ \\
$\begin{array}{l}\text { Neither unconfident } \\
\text { nor confident }\end{array}$ & $9(15.00 \%)$ & $9(15.00 \%)$ \\
Confident & $15(25.00 \%)$ & $3(5.00 \%)$ \\
\hline
\end{tabular}

Note. $\chi^{2}=24.00^{* * *}, d f=3$. Numbers in parentheses indicate column percentages. ${ }^{* * *} p<.001$

Table 4

Chi-square results showing the association between previous line-up experience and identification accuracy

\begin{tabular}{lcc}
\hline & \multicolumn{2}{c}{$\begin{array}{c}\text { Previous line-up } \\
\text { experience }\end{array}$} \\
\hline Identification accuracy & Yes & No \\
\hline Yes & $2(3.30 \%)$ & $0(0 \%)$ \\
No & $13(21.70 \%)$ & $45(75.00 \%)$
\end{tabular}

Note. $\chi^{2}=6.21^{*}, d f=1$. Numbers in parentheses indicate column percentages. ${ }^{*} p<.05$

are consistent with previous literature, which suggested that, when examining procedural difference effects between simultaneous and sequential techniques, utilising genuine or more realistic line-up procedures to those used within real police identifications, rates of accurate and inaccurate identifications remain similar (Wells et al., 2015; Wixted et al., 2016). Corresponding with Malpass et al. (2009) and Meissner et al. (2005), the present results suggest that when removing the memory component in line with the mock witness paradigm, sequential line-up procedures provide little superior effects upon eyewitness identifications than those obtained within traditional simultaneous line-ups. Although the present findings appear to contradict previous research finding evidence of a sequential superiority effect (Lindsay \& Wells, 1985; Melara et al., 1989), proponents of the mock witness paradigm, Doob and Kirshenbaum (1973), and Valentine and Heaton (1999), outline that rather than displaying deficiencies in procedural performance, lack of significant differences between procedures indicates instead that no aspect of either line-up's construction unfairly influences identifications made. The present findings are therefore important for police practice as they reveal that, while the interaction of eyewitness memory may result in varying levels of mistaken identification, when the memory component is removed procedurally, the 
underlying constructions of sequential and simultaneous line-ups are equally fair.

The present results also revealed significant differences in eyewitness confidence between line-up procedures. Participants making identifications in the simultaneous procedure were significantly more likely to be confident in identifications irrespective of accuracy and, conversely, in the sequential line-up procedure individuals were significantly less likely to be confident in identifications made than anticipated. These findings are in contrast to research by Dobolyi and Dodson (2013) in that, rather than indicating sequential absolute judgments to result in greater witness confidence, witnesses were in fact less likely to be confident in selections made than identifications made using simultaneous relative judgements. One possible explanation may be that, contrasting with what the aforementioned authors suggest, confidence in identification is established through witnesses being required to comparatively assess each line-up member against one another and form a logical conclusion about the likelihood of being accurate in that selection when matched to their memory of the perpetrator, rather than making a more abstract identification in sequential procedures. While limited research has sought to examine the confidence associated with identifications between line-up types in this way, much research has highlighted the complex relationship between confidence and accuracy, with a multitude of mediating factors found to influence it (Lindsay, 1986; Sporer et al., 1995). Therefore, the present findings are important in demonstrating the need for future research seeking to clarify further the impact of line-up type on eyewitness confidence rates and the accuracy of such identifications within varying line-up procedures, when controls for possible mediating factors are employed. Extrapolating a more direct causal relationship would provide courts with the necessary understanding to advise jurors of when caution must be applied to eyewitness identifications, irrespective of the confidence observed. Currently the US Supreme Court deems confidence of eyewitness evidence to be a measure of its reliability (see Dobolyi \& Dodson, 2013), and a multitude of research has shown the predictive ability of witness confidence upon jury decisions (Cutler et al., 1990). However, with current findings being in direct opposition to the latest research underpinning such legal practice, and ever growing DNA exonerations highlighting the fallibility of jury reliance upon mistaken eyewitness identifications (Innocence Project, 2015), further research is required.

Regarding demographic estimators, the present research obtained no evidence to support an association between identification accuracy and gender, age, occupation or level of education. While the results sit in contrast to research that indicated age to be an important determinant of identification accuracy
(Wright \& Stroud, 2002; Yarmey, 1993), the findings correspond with literature on the remaining estimator variables, largely shown to have little impact on identification performance (Shapiro \& Penrod, 1986; Wells \& Olson, 2003). A limitation of the present study concerns the lack of examination of the relationship between more psychologically grounded constructs and eyewitness identification accuracy. Moreover, although few attempts have been made to link line-up performance to personality characteristics, previous studies found that those high in the trait of anxiety made fewer mistaken identifications (Shapiro \& Penrod, 1986), and high self-monitors, who adapt their behaviour based on social acceptance needs, displayed greater accuracy in identifications (Hosch \& Platz, 1984). Upon also considering recent research indicating the influence that personality traits (empathy, egocentricity) and social identification can have on offender cognitions and thinking patterns (Boduszek, Dhingra, \& Debowska, 2016; Sherretts \& Willmott, 2016), the need to establish whether similar personality factors may influence eyewitness decision making processes in future research remains.

Interestingly, the present findings did indicate identification accuracy to be associated with previous line-up experience. Witnesses with experience of undertaking real line-ups in the past were significantly more accurate in their target selections than those with no previous experience. While some research has shown that police officers' own identification performance improves with experience in the position (Wells \& Olson, 2003), to the authors' knowledge research is yet to evaluate the effects of previous line-up experience on eyewitness performance, or report evidence supporting the idea that identification accuracy can be improved with experience. While the findings provide important contributions to the eyewitness literature, the results also offer significant practical implications for police line-up procedures, the suggestion being that pseudo-line-up identifications prior to an eyewitness's genuine line-up identification may lead to increased accurate identifications and fewer inaccurate identifications. Boccaccini, Gordon and Brodsky (2005), investigating the impact of witness preparation on the delivery of testimony at trial, found evidence to be more complete and confidently conveyed following practice attempts. Such findings, alongside the current results, lead the researchers to suggest that the development of formal guidelines allowing witnesses to receive brief training and make practice attempts at line-up identifications, may itself lead to improvements in eyewitness identification accuracy rates. Hence, future research should seek to examine more rigorously the beneficial effects of practice on line-up performance, making distinctions between sequential and simultaneous line-up procedures, as 
well as monitoring rates of both misidentification and accurate identification.

Given the significance of the present study findings overall, and novel contributions outlined for police practice and evidential policy, future research should seek to address certain limitations evident within the current research. Alongside acknowledging the need for inclusion of personality assessments, the need to replicate the present findings within a more formal policing environment is required. Despite using an array of images derived from a genuine police investigation alongside an attempt to simulate the layout of a police interview room, the conditions under which participants observed photographs were more akin to laboratory settings than a police station - a factor which some research has shown to impact the strength and direction of results (Wixted et al., 2016). Furthermore, participants were not actual witnesses to the crime in which they were asked to make line-up identifications about and based selections wholly upon standardised descriptions provided to them. Although this is a common technique used within eyewitness identification research (Tredoux, 1999; Valentine \& Heaton, 1999; Wells \& Bradfield, 1999) undoubtedly drawing conclusions on witness identification accuracy from such stimulated conditions requires that the findings obtained be interpreted with caution. Therefore, future replications of the present study would benefit from greater ecological validity derived from testing in more realistic policing surroundings and perhaps using actual witnesses to crimes identifications are made in respect of. Due to the somewhat exploratory nature of the present aims, the study sample was also relatively small, which, although varying widely in terms of demographic factors, future research should seek to improve upon. Replication and development of current findings could have major implications for police line-up procedures, providing greater insight into the structural fairness and confidence interaction between sequential and simultaneous procedures, alongside possible enhancements in identification accuracy, irrespective of procedures currently in place, through a simple process of permitting eyewitnesses practice attempts. Importantly, however, upon considering the mass of research and case exonerations indicating jurors' (over)reliance on eyewitness identification evidence (Semmler et al., 2011), is the potential for the current findings to safeguard against unsafe verdict outcomes in the future. Within the UK, recent research indicating the negative impact that juror attitudes and misconceptions can have on verdict outcomes led to the requirement that judges advise jurors against such bias within related cases (Ellison \& Munro, 2014). The current findings suggest, beyond a simple relationship with accuracy, that eyewitness confidence in identifications is also dependent on the line-up procedure that witnesses are exposed to and may in itself act as a moderating factor. Given the implications of such developed understanding of the confidence-accuracy relationship, and the undoubted need for further research, there emerges an opportunity to ensure judges and in turn jurors are more reliably informed about the inferences that ought to be made from such confident witnesses.

\section{CONCLUSIONS}

Given the lack of agreement about which line-up procedure is supposedly superior, this study sought to examine variations between different line-up types. The present research provides evidence supporting the comparable fairness of both line-up procedures when adopting the mock witness paradigm, with no evidence of a sequential-superiority effect upon removing the memory component of identifications. New insight into the interaction of eyewitness confidence between line-up techniques, contrasting with past research findings, offers an alternative account of witness confidence whereby increased confidence appears based on relative comparative assessments of different line-up members from which calculated conclusions within simultaneous line-ups are made but reductions in eyewitness confidence levels are attained when abstract isolated identifications within sequential procedures are made. Furthermore, evidence of practice effects increasing the accuracy of identification provides simple yet possibly substantially beneficial future implications for police line-up practice and safer jury decisions when considering the reliance on identification evidence. Although questions remain concerning the superiority of sequential-simultaneous line-ups effects, application of the often neglected mock witness paradigm allowed for advances in understanding of the different line-up techniques and future research developments to become apparent. Through the continued growth of empirical research set out in this study, the implications for police practice and safer verdict outcomes will continue to progress and be ensured. However, continued research in this field is required not only to reduce mistaken eyewitness identifications that result in wrongful convictions, but also to ensure that such occurrences result in the real perpetrators being brought to justice.

\section{RefERENCES}

Boccaccini, M. T., Gordon, T., \& Brodsky, S. L. (2005). Witness preparation training with real and simulated criminal defendants. Behavioral Sciences \& the Law, 23, 659-687.

Boduszek, D., Dhingra, K., \& Debowska, A. (2016). The moderating role of psychopathic traits in the relationship between period of confinement and 
criminal social identity in a sample of juvenile prisoners. Journal of Criminal Justice, 44, 30-35.

Bothwell, R. K., Deffenbacher, K. A., \& Brigham, J. C. (1987). Correlation of eyewitness accuracy and confidence: Optimality hypothesis revisited. Journal of Applied Psychology, 72, 691.

Bradfield, A. L., \& Wells, G. L. (2000). The perceived validity of eyewitness identification testimony: A test of the five Biggers criteria. Law and Human Behavior, 24, 581-594.

Brewer, N., \& Wells, G. L. (2006). The Confidence-Accuracy relationship in eyewitness identification: Effects of Lineup Instructions, Foil similarity, and target-absent base rates. Journal of Experimental Psychology: Applied, 12, 11-30.

Brigham, J. C., \& Bothwell, R. K. (1983). The ability of prospective jurors to estimate the accuracy of eyewitness identifications. Law and Human Behavior, 7, 19-30.

British Psychological Society. (2014). Code of Human Research Ethics. Leicester: BPS.

Brown, E., Deffenbacher, K., \& Sturgill, W. (1977). Memory for faces and the circumstances of encounter. Journal of Applied Psychology, 62, 311.

Carlson, C. A., Gronlund, S. D., \& Clark, S. E. (2008). Lineup Composition, suspect position, and the sequential lineup advantage. Journal of Experimental Psychology: Applied, 17, 1-11.

Cutler, B. L., \& Penrod, P. O. (1988). Improving the reliability of eyewitness identification: Lineup construction and presentation. Journal of Applied Psychology, 73, 281-290.

Cutler, B. L., Penrod, S. D., \& Dexter, H. R. (1990). Juror sensitivity to eyewitness identification evidence. Law and Human Behavior, 14, 185.

Deffenbacher, K. A. (1980). Eyewitness accuracy and confidence. Law and Human Behavior, 4, 243-260.

Deffenbacher, K. A., \& Loftus, E. F. (1982). Do jurors share a common understanding concerning eyewitness behavior? Law and Human Behavior, 6, 15-30.

Devlin, L. P. (1976). Report to the Secretary of State for the Home Department on the Departmental Committee on Evidence of Identification in Criminal Cases. London: HMSO.

Dobolyi, D. G., \& Dodson, C. S. (2013). Eyewitness confidence in simultaneous and sequential lineups: A criterion shift account for sequential mistaken identification overconfidence. Journal of Experimental Psychology: Applied, 19, 345.

Doob, A. N., \& Kirshenbaum, H. M. (1973). Bias in Police line-ups: partial remembering. Journal of Police Science and Administration, 1, 287-293.

Dysart, J. E., \& Lindsay, R. C. L. (2001). A preidentification questioning effect: Serendipitously increasing correct rejection. Law and Human Behaviour, 25, 155-165.
Ebbesen, E. B., \& Flowe, H. (2002). Simultaneous v. Sequential lineups: What do we really know? Unpublished manuscript.

Ellison, L., \& Munro, V. E. (2014). 'Telling tales': exploring narratives of life and law within the (mock) jury room. Legal Studies, n/a-n/a. doi: 10.1111/lest. 12051

Erickson, W. B., Lampinen, J. M., \& Moore, K. N. (2016). Eyewitness identifications by older and younger adults: a meta-analysis and discussion. Journal of Police and Criminal Psychology, 31, 108-121.

Field, A. (2009). Discovering Statistics using SPSS ( $3^{\text {rd }}$ ed.). London, England: Sage.

Garrett, B. (2011). Convicting the innocent. Massachusetts: Harvard University Press.

Hosch, H. M., \& Platz, S. J. (1984). Self-monitoring and eyewitness accuracy. Personality and Social Psychology Bulletin, 10, 289-292.

Innocence Project. (2015). The Causes of Wrongful Conviction. Retrieved from http://www.innocenceproject.org/\#causes.

Kassin, S., Tubb, V., Hosch, H., \& Memon, A. (2001). On the 'General acceptance' of eyewitness testimony research: a new survey of the experts. American Psychologist, 56, 405-416.

Kneller, W., Memon, A., \& Stevenage, S. (2001). Simultaneous and sequential lineups: Decision processes of accurate and inaccurate eyewitnesses. Applied Cognitive Psychology, 15, 659-671.

Lindsay, R. C. (1986). Confidence and accuracy of eyewitness identification from lineups. Law and Human Behavior, 10, 229-239.

Lindsay, R. C., \& Bellinger, K. (1999). Alternatives to the sequential lineup: The importance of controlling the pictures. Journal of Applied Psychology, 84, 315-321.

Lindsay, R. C., Lea, J. A., \& Fulford, J. A. (1991). Sequential lineup presentation: Technique matters. Journal of Applied Psychology, 76, 741-745.

Lindsay, R. C., \& Wells, G. L. (1985). Improving eyewitness identifications from lineups: Simultaneous versus sequential lineup presentation. Journal of Applied Psychology, 70, 556-564.

Lindsay, R. C., Wells, G. L., \& O’Connor, F. J. (1989). Mock-juror belief of accurate and inaccurate eyewitnesses. Law and Human Behavior, 13, 333-339.

Malpass, R. S., Tredoux, C. G., \& McQuiston-Surrett, D. (2009). Response to Lindsay, Mansour, Beaudry, Leach and Bertrands 'sequential lineup presentation: Patterns and Policy'. Legal and Criminological Psychology, 14, 25-30.

McQuiston-Surrett, D., Malpass, R. S., \&Tredoux, C. G. (2006). Sequential vs. Simultaneous lineups: A review of methods, data and theory. Psychology, Public Policy and Law, 12, 137-169.

Meissner, C. A., \& Brigham, J. C. (2001). Thirty years of investigating the own-race bias in memory for faces: A meta-analytic review. Psychology, Public Policy, and Law, 7, 3-35. 
Meissner, C. A., Tredoux, C. G., Parker, J. F., \& MacLin, O. H. (2005). Eyewitness decisions in simultaneous and sequential lineups: A dual-process signal detection theory analysis. Memory \& Cognition, 33, 783-792.

Melara, R. D., DeWitt-Rickards, T. S., \& O’Brien, T. P. (1989). Enhancing lineup identification accuracy: Two codes are better than one. Journal of Applied Psychology, 74, 706-713.

Penrod, S., \& Cutler, B. (1995). Witness confidence and witness accuracy: Assessing their forensic relation. Psychology, Public Policy, and Law, 1, 817.

Police Executive Research Forum. (2013). A National Survey of Eyewitness Identification Procedures in Law Enforcement Agencies (US Department of Justice, Washington, DC).

Pozzulo, J. D., \& Lindsay, R. C. (1998). Identification accuracy of children versus adults: a meta-analysis. Law and Human Behavior, 22, 549-570.

Scheck, B., Neufield, P., \& Dwyer, J. (2000). Actual Innocence: Five Days to Execution and other Dispatches from the Wrongfully Convicted. London: Penguin.

Semmler, C., Brewer, N., \& Douglass, A. B. (2011). Jurors believe eyewitnesses. In B. L. Cutler (ed.), Conviction of the innocent: Lessons from psychological research (pp. 185-209). Washington, DC: American Psychological Association.

Shapiro, P. N., \& Penrod, S. (1986). Meta-analysis of facial identification studies. Psychological Bulletin, 100, 139.

Sherretts, N., \& Willmott, D. (2016). Construct validity and dimensionality of the measure of criminal social identity using data drawn from American, Pakistani, and Polish inmates. Journal of Criminal Psychology, 6, 134-143.

Sporer, S. L., Penrod, S., Read, D., \& Cutler, B. (1995). Choosing, confidence, and accuracy: A meta-analysis of the confidence-accuracy relation in eyewitness identification studies. Psychological Bulletin, 118, 315-327.

Steblay, N., Dysart, J., Fulero, S., \& Lindsay, R. C. L. (2001). Eyewitness accuracy rates in sequential and simultaneous lineup presentations: A meta-analytic comparison. Law and Human Behavior, 25, 459-447.

Steblay, N. K., Dysart, J. E., \& Wells, G. L. (2011). Seventy-two tests of the sequential lineup superiority effect: A meta-analysis and policy discussion. Psychology, Public Policy, and Law, 17, 99-139.

Tredoux, C. G. (1999). Statistical considerations when determining measures of lineup size and lineup bias. Applied Cognitive Psychology, 13, 9-26.

Valentine, T., \& Heaton, P. (1999). An Evaluation of the fairness of police line-ups and video identifications. Applied Cognitive Psychology, 13, 59-72.

Wells, G. (1978). Applied eyewitness-testimony research: System variables and estimator variables.
Journal of Personality and Social Psychology, 36, 1546-1557.

Wells, G. (1984). The psychology of lineup identifications. Journal of Applied Social Psychology, 14, 89-103.

Wells, G. (1993). What do we know about eyewitness identification? American Psychologist, 48, 553-571.

Wells, G. (2006). Eyewitness identification: systemic reforms. Wisconsin Law Review, 5, 615-643.

Wells, G., \& Bradfield, A. L. (1999). Distortions in eyewitnesses' recollections: Can the postidentification-feedback effect be moderated? Psychological Science, 10, 138-144.

Wells, G., Memon, A., \& Penrod, S. (2006). Eyewitness evidence: Improving its probative value. Psychological Science in the Public Interest, 7, 45-75.

Wells, G. L., \& Murray, D. M. (1984). Eyewitness confidence. In G. L. Wells \& E. F. Loftus (eds.), Eyewitness testimony: Psychological perspectives (pp. 155-170). Cambridge: Cambridge University Press.

Wells, G., \& Olson, E. (2003). Eyewitness identification. Annual Review of Psychology, 54, 277-295.

Wells, G., Small, M., Penrod, S., Malpass, R., Fulero, S., \& Brimacombe, C. (1998). Eyewitness Identification procedures: Recommendations for line-ups and photospreads. Law and Human Behaviour, 22, 603-647.

Wells, G. L., Steblay, N. K., \& Dysart, J. E. (2015). Double-blind photo lineups using actual eyewitnesses: An experimental test of a sequential versus simultaneous lineup procedure. Law and $\mathrm{Hu}$ man Behavior, 39, 1-14.

Wixted, J. T., Mickes, L., Dunn, J. C., Clark, S. E., \& Wells, W. (2016). Estimating the reliability of eyewitness identifications from police lineups. Proceedings of the National Academy of Sciences, 113, 304-309.

Wogalter, M. S., Malpass, R. S., \& McQuiston, D. E. (2004). A national survey of U.S. police on preparation and conduct of identification lineups. Psychology, Crime \& Law, 10, 69-82.

World Medical Association. (2013). WMA declaration of Helsinki: Ethical principles for medical research involving human subjects. Retrieved from http:// www.wma.net/en/30publications/10policies/b3/

Wright, D. B., \& Stroud, J. N. (2002). Age differences in lineup identification accuracy: People are better with their own age. Law and Human Behaviour, 26, 641-654.

Yarmey, A. D. (1993). Adult Age and gender differences in eyewitness recall in field settings. Journal of Applied Social Psychology, 23, 1921-1932. 